\title{
Annexin A1-mediated inhibition of inflammatory cytokines may facilitate the resolution of inflammation in acute radiation-induced lung injury
}

\author{
GAOHUA HAN $^{1 *}$, KAIJIN LU ${ }^{2}$, WANSONG XU ${ }^{3}$, SIHUI ZHANG ${ }^{1 *}$, \\ JUNXING HUANG ${ }^{1}$, CHUNLEI DAI ${ }^{4}$, GUANGZHI SUN ${ }^{3}$ and $\mathrm{JUN} \mathrm{YE}^{5}$
}

\begin{abstract}
Departments of ${ }^{1}$ Oncology and ${ }^{2}$ Thoracic Surgery; ${ }^{3}$ Radiation Therapy Center; ${ }^{4}$ Medical Imaging Center; ${ }^{5}$ Central Laboratory, The Fifth Affiliated Hospital of Nantong University, Taizhou People's Hospital, Taizhou, Jiangsu 225300, P.R. China
\end{abstract}

Received April 5, 2018; Accepted February 14, 2019

DOI: $10.3892 / \mathrm{ol} .2019 .10317$

\begin{abstract}
The present study evaluated the role of annexin A1 (ANXA1) in the treatment of acute radiation-induced lung injury (RILI) and investigated the mechanism of its action. The expression of ANXA1, interleukin-6 (IL-6) and myeloperoxidase (MPO) in the plasma of patients with RILI prior to and following hormonotherapy was assessed by enzyme-linked immunosorbent assay. The association of plasma ANXA1 concentration with clinical effect, and the correlation between the expression of ANXA1 and that of IL- 6 and MPO were evaluated. ANXA1 was overexpressed or knocked down in a macrophage cell line, and its impact on IL-6 and MPO expression was measured. Following glucocorticoid hormonotherapy, patients with RILI exhibited a higher plasma concentration of ANXA1 compared with that prior to treatment, while IL-6 and MPO levels were lower. The concentration of ANXA1 in plasma was negatively correlated with IL-6 and MPO levels, with a correlation coefficient of -0.492 and -0.437 , respectively $(\mathrm{P}<0.001)$. The increasing concentration of ANXA1 in plasma following treatment was associated with the clinical effect in patients with RILI $(\mathrm{P}=0.007)$. The expression levels of of IL-6 and MPO were inhibited both in the cytoplasm and in the culture solution, when ANXA1 expression was upregulated in a macrophage cell line. In conclusion, ANXA1 inhibited the synthesis and secretion of IL-6 and MPO inflammatory cytokines, indicating that ANXA1 may have therapeutic potential as a treatment target for RILI.
\end{abstract}

Correspondence to: Dr Junxing Huang, Department of Oncology, The Fifth Affiliated Hospital of Nantong University, Taizhou People's Hospital, 399 South Hailing Road, Hailing, Taizhou, Jiangsu 225300, P.R. China

E-mail: hjxtz@sina.cn

${ }^{*}$ Contributed equally

Key words: annexin A1, interleukin-6, myeloperoxidase, radiationinduced lung injury

\section{Introduction}

Radiation-induced lung injury (RILI) is the most common dose-limiting side effect in patients with thoracic tumors following radiotherapy $(1,2)$. Various strategies and drugs have been applied for the prevention and treatment of RILI, with poor therapeutic effect (3-6). Glucocorticoids have been administrated in numerous clinical studies for the treatment of acute RILI (1,7-9). However, prolonged usage of high doses of glucocorticoids can lead to a number of side effects, including osteoporosis, abnormal glucose metabolism, digestive tract ulcers and infection (10). Averting the side effects of radiotherapy without affecting the clinical benefits is an important goal.

The pathogenesis of RILI is complicated. Alveolar type II epithelial cells and lung capillary endothelial cells are the main targets of RILI $(11,12)$, producing pro-inflammatory cytokines, including interleukin-6 (IL-6) (7) and transforming growth factor- $\beta 1$ (TGF- $\beta 1$ ) (13). Macrophages are the most important secretory cells of IL- 6 and TGF- $\beta 1$. In addition, macrophages also produce tumor necrosis factor- $\alpha$ (TNF- $\alpha$ ), insulin-like growth factor 1 , platelet-derived growth factor- $\beta$, macrophage-derived chemokines and other cytokines, These cytokines enhance the permeability of lung capillary endothelium and the chemotactic recruitment of monocytes, macrophages and neutrophils to the injured lung tissue in the target area. The inflammatory signal is amplified due to increased production of IL-6 and the generation of myeloperoxidase (MPO) by neutrophils, aggravating local inflammation and leading to damage of the alveolar structure (14-16). In addition, the secretion of TGF- $\beta$ by macrophages can also lead to the progression of RILI into chronic pulmonary fibrosis. As a result, macrophages and neutrophils are influential in this process.

Annexin A1 (ANXA1) is a protein regulated by glucocorticoids. ANXA1 mimics the anti-inflammatory effect of glucocorticoids $(17,18)$. ANXA1 is expressed in neutrophils, eosinophils and subcellular granules of monocytes and macrophages in the peripheral blood (19), and it inhibits the migration of neutrophils (20). Thus, ANXA1 has clinical potential for the treatment of RILI. 
The role of ANXA1 in the pathogenesis of acute RILI and the mechanism of its clinical benefit on RILI are unclear. The present study evaluated the therapeutic potential of ANXA1 against RILI by assessing ANXA1 expression in the plasma of patients with RILI prior to and following 4 weeks of glucocorticoid treatment. The anti-inflammatory mechanism of ANXA1 was investigated by upregulating and downregulating ANXA1 expression in a macrophage cell line to assess the impact on IL-6 and MPO expression. Further understanding of the anti-inflammatory effect of ANXA1 on RILI may provide pre-clinical evidence to support targeting ANXA1 in the prevention and treatment of RILI.

\section{Materials and methods}

Subject information. A total of 50 patients with thoracic tumors suffering with RILI following radiotherapy between January 2014 and October 2016 at Taizhou People's Hospital (Taizhou, China) were included in the present study. The patients had experienced RILI with a severity of grade 2 or more after therapy, according to the Common Terminology Criteria for Adverse Events from the National Cancer Institute (version 3.0; National Institutes of Health, Rockville, MD, USA) (21). A total of 45 patients with complete clinical data were involved in the result analysis, including 25 males and 20 females, and the age ranging between 47 and 75 years old (median, 63.5 years). The research was approved by the Ethics Committee of Taizhou People's Hospital, and written informed consent was provided by each patient prior to the study.

Treatment of acute RILI and evaluation of treatment outcome. Glucocorticoid (methylprednisolone or dexamethasone) was administered to patients with RILI as the basic comprehensive treatment immediately after diagnosis. Methylprednisolone was administrated intravenously (iv), with a starting dose 1-2 $\mathrm{mg} / \mathrm{kg} / \mathrm{day}$, and the dose would reduce by half every 4 days. Dexamethasone was administrated with a starting dose of $10 \mathrm{mg} / \mathrm{day}$ iv, and reduced as described previously. Routine blood examination was performed weekly during treatment, and a thoracic computed tomography scan was performed after 4 weeks of treatment. Response to treatment was assessed by alleviation of clinical symptoms (e.g. cough, fever, chest distress, dyspnea) and imaging (X-ray, CT scan) and laboratory findings (white blood cell count). The treatment outcome was evaluated comprehensively based on the patients' clinical symptoms and the aforementioned indicators, including CT scan and white blood cell count and neutrophils count.

Neutrophil count and ELISA. Peripheral venous blood was drawn from each patient weekly from the time of diagnosis until 1 month post-treatment. Then, the neutrophil count was measured through routine blood tests, and the expression of ANXA1, IL-6 and MPO was assessed using ELISA in the plasma extracted by centrifugation from the blood samples. The ANXA1 (cat. no. ab222868; antibody name: AF3770) and IL-6 (cat. no. PD6050; antibody name: MAB206) kits, and the primary antibody were purchased from R\&D Systems China Co., Ltd. The MPO kit was purchased from Abcam Shanghai Co., Ltd. (cat. no. ab119605; antibody name: ab45977). Measurements were performed in triplicate for each sample.
The absorbance was read at $450 \mathrm{~nm}$ and the protein levels were calculated based on the standard curve. Blood samples from 20 healthy donors were also assessed as the negative control.

Plasmid construction for ANXA1 expression. Eca109 human esophageal cancer cells, purchased from Shanghai Institute of Biochemistry and Cell Biology Chinese Academy of Sciences were cultured in DMEM with $10 \%$ fetal bovine serum (FBS; Gibco; Thermo Fisher Scientific, Inc.) and antibiotics at $37^{\circ} \mathrm{C}$ with $5 \% \mathrm{CO}_{2}$. RNA from Eca109 human esophageal cancer cells was extracted using TRIzol ${ }^{\circledR}$ reagent (Invitrogen; Thermo Fisher Scientific, Inc., Shanghai, China). The AMV reverse transcription kit (Promega Corporation) was subsequently used for reverse transcription to obtain the cDNA which was used as a template, together with ANXA1 primers (synthesized by Invitrogen; Thermo Fisher Scientific, Inc. Shanghai, China) for PCR amplification: The primer sequences were as follows: Sense, 5'-ATGGCAATGGTATCAGAATTC CTC-3' and antisense , 5'-TTAGTTTCCTCCACAAAG AGCCACC-3'. PrimerSTAR HS DNA polymerase (Takara Biotechnology Co., Ltd., Dalian, China) was used for amplification. The reaction parameters were as follows: $95^{\circ} \mathrm{C} \times 3 \mathrm{~min}$, $94^{\circ} \mathrm{C} \times 30 \mathrm{sec}, 58^{\circ} \mathrm{C} \times 30 \mathrm{sec}, 72^{\circ} \mathrm{C} \times 5 \mathrm{~min}, 72^{\circ} \mathrm{C} \times 5 \mathrm{~min}$, for 27 cycles. The PCR product was purified using the QIAquick PCR Purification kit (Qiagen China Co., Ltd., Shanghai, China). ANXA1 cDNA was cleaved with the restriction endonucleases XhoI and BamHI (Fermentas; Thermo Fisher Scientific, Inc., Pittsburgh, PA, USA) and ligated with the pIRES2-EGFP vector (Takara Biotechnology Co., Ltd.) to form a pIRES2-EGFP-ANXA1 (pIRES2-ANXA1) expression plasmid. The plasmid was expressed in competent Escherichia coli DH5 $\alpha$ cells (Shanghai Institute of Biochemistry and Cell Biology Chinese Academy of Sciences) and purified using a mini-prep kit from Axygen Biosciences (Union City, CA, USA). The construct was examined by enzyme digestion and sequenced as previously described (22).

Differentiation and cultivation of M2 macrophages. Human peripheral-blood monocytes are used as an established in vitro system for generating macrophages, and monocytic cell lines, as THP-1 cells have been considered as a possible alternative (23-25). In the present study, THP-1 cells were acquired from the Shanghai Institute of Biochemistry and Cell Biology, and were cultured in RPMI-1640 medium (Thermo Fisher Scientific, Inc.) supplemented with non-heat-treated 10\% FBS (Invitrogen; Thermo Fisher Scientific, Inc.), $2 \mathrm{mM}$ L-glutamine, $0.05 \mathrm{mM} \beta$-mercaptoethanol, 4,500 mg/1 glucose, $100 \mathrm{U} / \mathrm{ml}$ penicillin and $100 \mu \mathrm{g} / \mathrm{ml}$ streptomycin at $37^{\circ} \mathrm{C}$ with $5 \% \mathrm{CO}_{2}$. THP-1 cells were kept at a minimum density of $5 \times 10^{5}$ cells $/ \mathrm{ml}$ and were passaged when reaching $5 \times 10^{6}$ cells $/ \mathrm{ml}$. The cells were induced to differentiate into M2 macrophages by PMA (Sigma-Aldrich; Merck KGaA) at a final concentration of $150 \mathrm{ng} / \mathrm{ml}$ and IL-4 at a final concentration of $20 \mathrm{ng} / \mathrm{ml}$ incubated for $48 \mathrm{~h}$. The cells were imaged using an optical microscope. Differentiation was verified by assessing expression of a marker of the M2 phenotype, macrophage mannose receptor 1 (CD206) (26-28). Cells were collected at $48 \mathrm{~h}$ after induction for detection. The induced cells were digested with trypsin and collected by centrifugation at $200 \mathrm{x} \mathrm{g}$ for $10 \mathrm{~min}$ at $4^{\circ} \mathrm{C}$ (induction group). Uninduced 
cells were centrifuged, as described previously, and collected (control group). The pellet was resuspended in PBS and the cells were washed with PBS solution twice. Then, the cells were suspended at $\sim 1 \times 10^{6}$ cells $/ \mathrm{ml}$ in PBS for further use. The Phycoerythrin (PE)-conjugated anti-CD206 monoclonal antibody (dilution, 1:20; cat. no: 555954; BD Pharmingen) was added to the cell suspension, which was subsequently incubated in the dark for $30 \mathrm{~min}$ at $4^{\circ} \mathrm{C}$. After two washes in PBS, the cells were resuspended with $2 \%$ paraformaldehyde (in cold PBS) and incubated for $20 \mathrm{~min}$ at $4^{\circ} \mathrm{C}$. Suspension was centrifuged at $200 \times \mathrm{g}$ for $5 \mathrm{~min}$ at $4^{\circ} \mathrm{C}$ and the pellet resuspended with glycine $0.1 \mathrm{M}$ (in cold PBS) and incubated for $10 \mathrm{~min}$ at $4^{\circ} \mathrm{C}$. Then, the last centrifugation of $5 \mathrm{~min}$ at $200 \mathrm{x}$ g at $4^{\circ} \mathrm{C}$ was performed before cell resuspension in $1 \mathrm{ml}$ of PBS and the expression of CD206 was measured using a flow cytometer (FACScalibur; BD Biosciences), and analyzed by the FlowJo 7.6.4 software (TreeStar Inc.).

Overexpression and inhibition of ANXA1 in THP-1 cells differentiated into M2 macrophages. THP-1 cells were induced into macrophage $48 \mathrm{~h}$ after transfection. The pIRES2-ANXA1 expression plasmid was transfected into THP-1 cells using Lipofectamine ${ }^{\circledR} 2000$ (Invitrogen; Thermo Fisher Scientific, Inc.). The pIRES2-EGFP empty plasmid was transfected as the control. Prior to transfection, the plasmid $(1 \mu \mathrm{g} / \mathrm{ul})$ was mixed with liposomes and allowed to stand for $20 \mathrm{~min}$. The mixture was dispensed into culture wells ( $2 \mu \mathrm{g}$ DNA and $5 \mathrm{ul}$ liposomes per well) following the manufacturer's protocol. The transfection efficiency was assessed by fluorescence microscopy and western blot analysis. The transfected THP-1 cells were then induced to generate ANXA1-overexpressing macrophages. Macrophages harboring the ANXA1 plasmid comprised the pIRES2-ANXA1 group and those with the empty plasmid comprised the no-load group. Non-transfected macrophages comprised the blank control. Each group of cells was partitioned into 3 wells and the experiments were repeated 3 times.

Small interfering RNAs (siRNAs) against ANXA1 were transfected into THP-1 cells to inhibit the expression of ANXA1. The siRNAs included 2 sequences targeting ANXA1 and a scrambled control sequence as follows: siRNA (a), 5'-CAG CGUCAACAGAUCAAAG-3'; siRNA (b), 5'-CCGAUCUGA GGACUUUGGU-3'; and control siRNA, 5'-CAGUCGCGU UUGCGACUGG-3.' These siRNA sequences were designed as previously described (29). The siRNAs were synthesized by Shanghai Sangon Company (Shanghai, China). After $48 \mathrm{~h}$ these transfected THP-1 cells were then induced to differentiate into macrophages. Macrophages transfected with siRNA (a) and siRNA (b) were designated as the siRNA (a) and siRNA (b) groups, respectively. Macrophages transfected with control siRNA or plasmid were designated as the siRNA (control) group or the no-load group, respectively. Non-transfected macrophages comprised the blank control group.

Western blot analysis. Macrophages in each well were trypsinized and total cell protein was extracted using cell lysis buffer (cat. no. P0013; Beyotime Institute of Biotechnology). Sample protein concentrations were determined for each group using the DC Protein assay kit (Bio-Rad Laboratories, Inc., Hercules, CA, USA). SDS-PAGE (15\%) was performed for each group using $50 \mu \mathrm{g}$ protein sample per lane, and proteins were then transferred from the gel to polyvinylidene difluoride membranes (EMD Millipore, Billerica, MA, USA). Following a 1-h incubation in blocking buffer (cat. no. C-0042; $5 \%$ bovine serum albumin; Xiamen, BOYAO Biotechnology Co., Ltd.) at $4^{\circ} \mathrm{C}$, membranes were incubated with the following primary antibodies at $4^{\circ} \mathrm{C}$ overnight with agitation: Anti-IL-6 (1:1,000; cat. no. RAB0307; Sigma-Aldrich; Merck KGaA), anti-ANXA1 (1:1,000; cat. no. SAB1405457; Sigma-Aldrich; Merck KGaA), anti-MPO (1:1,000; cat. no. 76923; Cell Signaling Technology, Inc., Danvers, MA, USA) and anti-GAPDH (1:3,000; cat.no. sc-47724; Santa Cruz Biotechnology, Inc., Dallas, TX, USA). Following washing with stripping buffer [ $\beta$-mercaptoethanol $342 \mu 1 ; 20 \%$ SDS $5 \mathrm{ml}$; Tris-Cl (pH 6.7) $3.125 \mathrm{ml}$; ddH2O $41.533 \mathrm{ml}$ to total volume $50 \mathrm{ml}$, the membranes were incubated with agitation at room temperature for $1 \mathrm{~h}$ with a secondary antibody (m-IgGк BP-HRP: sc-516102;Santa Cruz Biotechnology, Inc.) labeled with horseradish peroxidase in the presence of $2 \%$ bovine serum albumin (Invitrogen; Thermo Fisher Scientific, Inc), then HRP was visualized by Chemiluminescent Western Blot Detection kit (SuperSignal West Femto; Thermo Fisher Scientific, Inc.). The membranes were washed and imaged, and the bands were analyzed semi-quantitatively with ImageJ 1.8 software (https://imagej.nih.gov/ij/download.html).

Effect of altered expression of ANXA1 on expression of IL-6 and MPO. M2 macrophages in which ANXA1 was overexpressed or inhibited were resuspended for cell counting following transfection to ensure that the cell density in each well for further cultivation was the same. Following $72 \mathrm{~h}$ in culture, ELISA was performed on the medium to evaluate the level of IL-6 and MPO secreted by the macrophages, and western blot analysis was performed to evaluate the levels of IL-6 and MPO protein in the macrophages. ELISA was performed as aforementioned for peripheral venous blood samples.

Statistical analysis. Measurement data are presented as the mean \pm standard deviation. SPSS (version 19.0; IBM Corp., Armonk, NY, USA) was utilized to create the database. Differences between means of two groups were compared using independent-samples t-test and those among multiple groups were compared using one-way analysis of variance (ANOVA). ANOVA was used to compare the means among baseline group and 1,2,3 and 4 weeks after treatment groups. Then, the Least Significant Difference post hoc test was used to compare between every two groups. Associations between treatment outcome and ANXA1, IL-6 and MPO levels were compared using a $\chi^{2}$ test. Correlation analysis was performed using Spearman's rank correlation method. $\mathrm{P}<0.05$ was considered to indicate that a difference was statistically significant.

\section{Results}

ANXA1, IL-6 and MPO levels in the plasma of patients with RILI. Among the 45 cases with RILI, the baseline level of ANXA1, IL-6 and MPO in the plasma prior to glucocorticoid treatment was $317.35 \pm 191.06,258.45 \pm 172.32 \mathrm{pg} / \mathrm{ml}$ and $139.24 \pm 57.94 \mathrm{ng} / \mathrm{ml}$, respectively. The corresponding level of healthy control group was $22.75 \pm 9.56,41.05 \pm 12.33 \mathrm{pg} / \mathrm{ml}$ and $62.24 \pm 27.39 \mathrm{ng} / \mathrm{ml}$, respectively. There was significant 
difference of ANXA1, IL-6 and MPO between the baseline of RILI patients and the healthy control $(\mathrm{P}<0.001)$ Following glucocorticoid administration, the expression of ANXA1 increased gradually (ANOVA test, $\mathrm{F}=31.503 ; \mathrm{P}<0.001$ ). The post hoc test showed that ANXA1 of 1, 2, 3 and 4 weeks after treatment was significantly higher compared with that of baseline, ( $\mathrm{P}=0.003,<0.001,<0.001,<0.001$, respectively), while that of IL-6 and MPO decreased, and the number of neutrophils remained unchanged (Fig. 1). Spearman's correlation analysis indicated that the ANXA1 level in the plasma following glucocorticoid treatment was significantly negatively correlated with the levels of IL-6 and MPO, with a correlation coefficient of -0.974 and -0.956 , respectively ( $\mathrm{P}<0.001$; Fig. 2 ).

Association between treatment outcome and expression levels of ANXA1, IL-6 and MPO in patients with RILI. Among the 45 cases, recovery occurred in 20 patients 2 weeks after glucocorticoid treatment, and a further 11 patients with repeat symptoms were cured following 4 weeks of treatment. These 31 cases were considered to have had an efficient treatment outcome. Interstitial lung diseases combined with chronic lung infection occurred in the remaining 14 cases, which were considered to have progressive disease. Cases were grouped by these two outcomes-efficient or progressive group. According to the increase of ANXA1 after hormone treatment, patients were divided into two groups: Patients with more than twice the baseline level and patients with less than two times the baseline level. Similarly, patients were divided into two groups according to the decrease of IL-6 and MPO, which were less than half of the baseline level and more than half of the baseline level group. Then, $\chi^{2}$ testing was performed to compare treatment outcome to expression levels of ANXA1, IL-6 and MPO in plasma following glucocorticoid treatment. The results indicated that the expression levels of ANXA1, IL-6 and MPO were associated with the treatment outcome for RILI. The increased expression of ANXA1 following 4 weeks of treatment was associated with improved treatment outcome for RILI ( $\mathrm{P}=0.007)$, while decreased expression of IL-6 and MPO expression following 4 weeks of treatment was associated with improved treatment outcome $(\mathrm{P}=0.042$ and $\mathrm{P}=0.003$, respectively) (Table I).

Differentiation of THP-1 cells and transfection of $p$-IRES2-ANXA1. PMA and IL-4 were added to the culture medium of THP-1 cells to induce differentiation to an M2 macrophage phenotype. THP-1 cells were round or quasi-circular, uniform in size and suspended in culture medium (Fig. 3A) and became adherent, spindle-shaped or polygonal cells (Fig. 3B) after $48 \mathrm{~h}$ in the culture medium with PMA and IL-4, which expressed CD206 (Fig. 3C) in flow cytometry. These results indicated that THP-1 cells were successfully induced to differentiate into M2 macrophages. Successful ANXA1 plasmid transfection indicated by green fluorescence was observed by fluorescence microscopy in the pIRES2-ANXA1 group of cells (Fig. 3D). A similar appearance was noted in the no-load group. Green fluorescence was absent in the blank control group. The results of the present study demonstrated that THP-1 cells transfected with p-IRES2-ANXA1 plasmid could differentiate into M2 macrophages, which enabled stable expression of ANXA1.

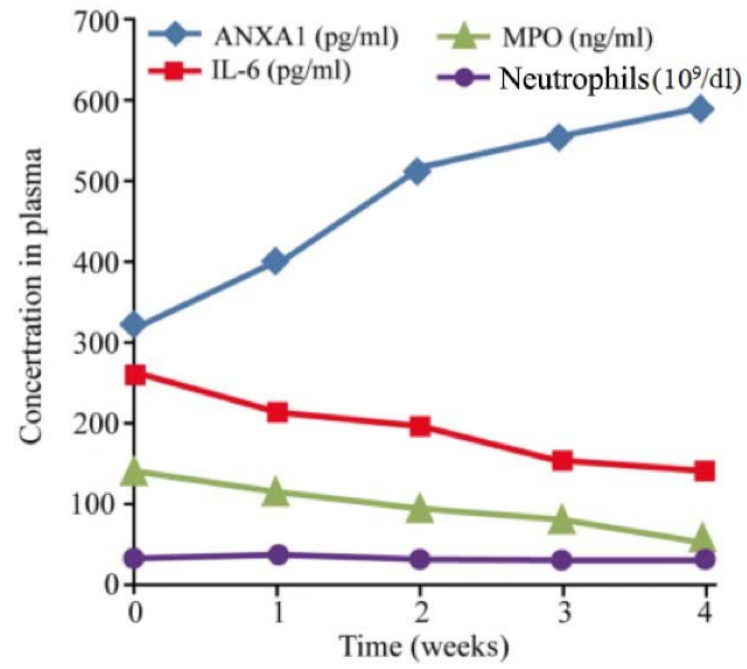

Figure 1. ANXA1, IL-6, MPO and neutrophils in the plasma of patients with acute radiation-induced lung injury following glucocorticoid administration for 4 weeks. ANXA1 at 4 weeks was significantly higher compared with the baseline level (317.35 vs. $586.75 \mathrm{pg} / \mathrm{ml} ; \mathrm{P}<0.001)$. IL-6 decreased gradually, and was significantly lower at 4 weeks compared with the baseline $(258.45$ vs. $139.35 \mathrm{pg} / \mathrm{ml} ; \mathrm{P}=0.003)$. The neutrophil count did not change with glucocorticoid administration $\left(33.5 \times 10^{9}\right.$ vs. $31.78 \times 10^{9}$ cells/dl; $\left.\mathrm{P}=0.247\right)$. MPO decreased and was notably lower compared with the baseline level following 4 weeks of glucocorticoid treatment $(139.24$ vs. $51.35 \mathrm{ng} / \mathrm{ml}$; $\mathrm{P}=0.018$ ). ANXA1, annexin A1; IL-6, interleukin 6; MPO, myeloperoxidase; GRA, granulocyte count, absolute.

Expression of ANXA1 in M2 macrophages following transfection. Following transfection of M2 macrophages with the p-IRES2-ANXA1 plasmid or siRNA against ANXA1, western blot analysis was used to determine ANXA1 protein expression. The cells transfected with pIRES2-ANXA1 exhibited a stronger ANXA1 signal compared with the cells in the blank control and no-load group. In macrophages transfected with siRNA (a) and siRNA (b), the ANXA1 band was weaker compared with that of the blank control and siRNA (control) groups (Fig. 4).

Effect of ANXA1 expression on IL-6 protein expression and secretion in macrophages. Western blot results revealed decreased IL-6 protein expression in macrophages transfected with p-IRES2-ANXA1, while ANXA1 inhibition caused by siRNA led to enhanced IL- 6 expression (Fig. 5A). The concentration of IL-6 in the culture medium exhibited a similar changing pattern, with a mean concentration of $215.23 \pm 42.11 \mathrm{pg} / \mathrm{ml}$ in the blank control group, $103.62 \pm 28.26 \mathrm{pg} / \mathrm{ml}$ in the ANXA1 overexpression group, $271.73 \pm 67.83 \mathrm{pg} / \mathrm{ml}$ in the siRNA (a) group and $264.24 \pm 55.97 \mathrm{pg} / \mathrm{ml}$ in the siRNA (b) group (Fig. 5B). The concentration of IL- 6 in the culture medium of the siRNA (control) and no-load group was $217.71 \pm 52.34$ and $209.65 \pm 42.15 \mathrm{pg} / \mathrm{ml}$, respectively, which was similar to that in the blank control group, indicating that ANXA1 inhibited the synthesis of IL-6 in macrophages and subsequent secretion.

Effect of ANXA1 expression on protein expression and secretion of MPO. MPO protein expression decreased in macrophages transfected with p-IRES2-ANXA1, while ANXA1 inhibition enhanced MPO protein expression (Fig. 5C). ELISA 
Table I. Association between the clinical effect against RILI and the plasma levels of ANXA1, IL-6 and MPO at 4 weeks of glucocorticoid treatment.

\begin{tabular}{|c|c|c|c|c|c|c|}
\hline \multirow[b]{2}{*}{$\begin{array}{l}\text { Clinical effect } \\
\text { against RILI }\end{array}$} & \multicolumn{2}{|c|}{ ANXA1 in plasma } & \multicolumn{2}{|c|}{ IL-6 in plasma } & \multicolumn{2}{|c|}{ MPO in plasma } \\
\hline & $\begin{array}{c}>2 \mathrm{x} \text { baseline } \\
\text { level }\end{array}$ & $\begin{array}{c}<2 \mathrm{x} \text { baseline } \\
\text { level }\end{array}$ & $\begin{array}{c}<50 \% \text { of } \\
\text { baseline level }\end{array}$ & $\begin{array}{c}>50 \% \text { of } \\
\text { baseline level }\end{array}$ & $\begin{array}{c}<50 \% \text { of } \\
\text { baseline level }\end{array}$ & $\begin{array}{c}>50 \% \text { of } \\
\text { baseline level }\end{array}$ \\
\hline Efficient, $\mathrm{n}$ & 20 & 11 & 19 & 12 & 19 & 12 \\
\hline Progressive, $\mathrm{n}$ & 3 & 11 & 4 & 10 & 2 & 12 \\
\hline$\chi^{2}$ & 7.166 & & 4.132 & & 8.562 & \\
\hline P-value & 0.007 & & 0.042 & & 0.003 & \\
\hline
\end{tabular}

RILI, radiation-induced lung injury; ANXA1, annexin A1; IL-6, interleukin 6; MPO, myeloperoxidase.

A

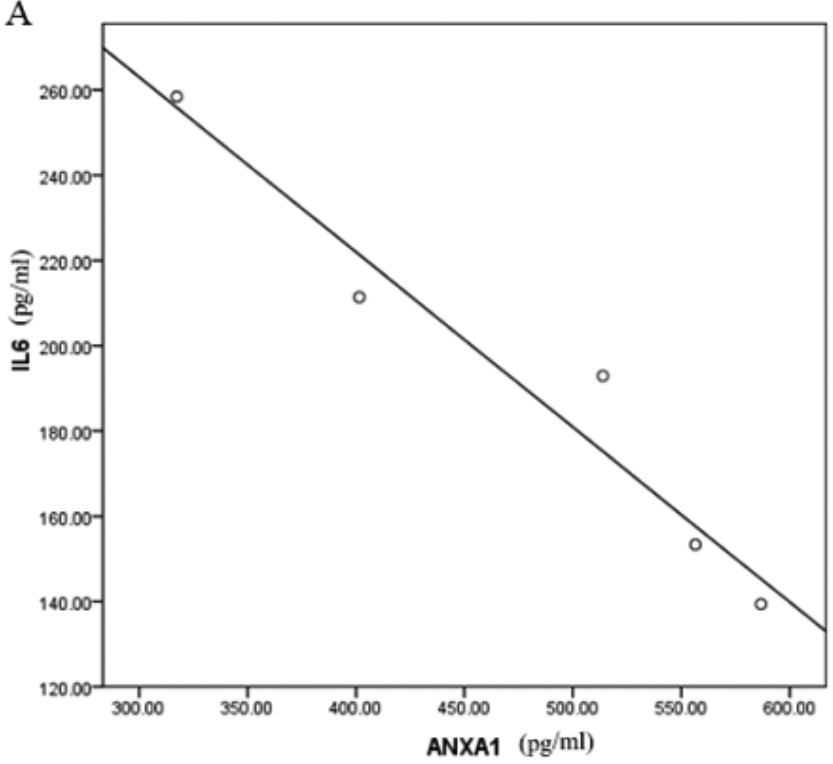

B

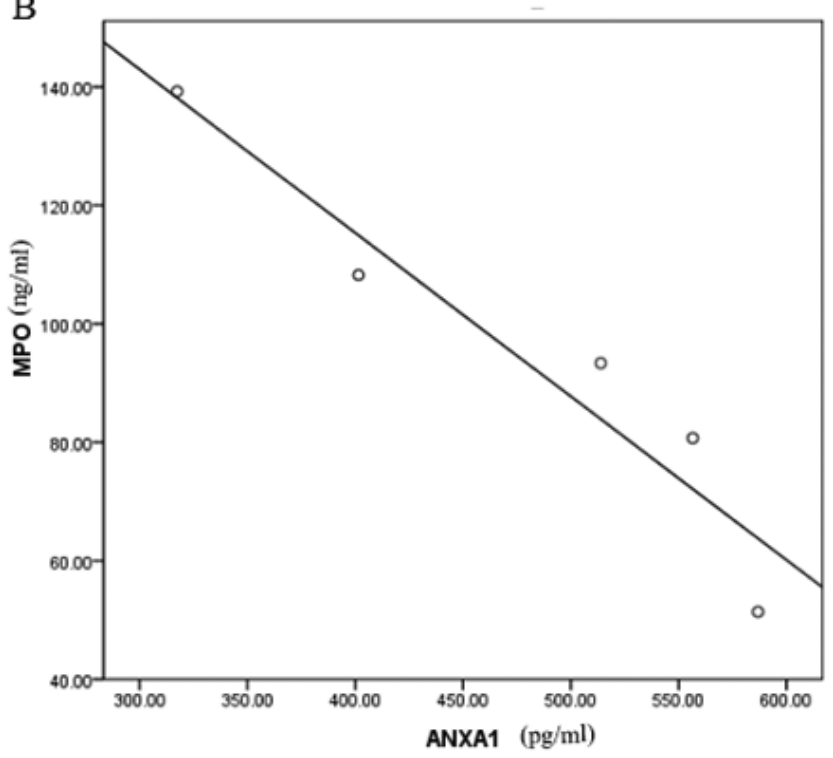

Figure 2. The correlation between the expression level of ANXA1 and IL-6 or MPO in plasma of patients with RILI treated with glucocorticoid. (A) Negative correlation between ANXA1 and IL-6; r=-0.974. (B) Negative correlation between ANXA1 and MPO, r=-0.956. ANXA1, annexin A1; IL-6, interleukin 6; MPO, myeloperoxidase; RILI, radiation-induced lung injury.

results demonstrated a similar pattern of MPO expression in the culture medium: $175.32 \pm 42.35 \mathrm{pg} / \mathrm{ml}$ in the blank control group, $73.04 \pm 15.06 \mathrm{pg} / \mathrm{ml}$ in the ANXA1 overexpression group, $214.15 \pm 59.37 \mathrm{pg} / \mathrm{ml}$ in the siRNA (a) group and $221.21 \pm 64.87 \mathrm{pg} / \mathrm{ml}$ in the siRNA (b) group (Fig. 5D). The respective levels in the siRNA (control) and no-load group $(167.51 \pm 38.26$ and $171.92 \pm 50.07 \mathrm{pg} / \mathrm{ml})$ were similar to that in the blank control group, indicating that ANXA1 inhibited the synthesis of MPO in macrophages and subsequent secretion.

\section{Discussion}

To date, efforts to treat acute RILI have focused on neutralizing pro-inflammatory cytokines or attenuating the infiltration of inflammatory cells (5). These efforts have been hampered by a lack of knowledge of the mechanisms of the cytokine or signaling pathways involved in the pathogenesis of RILI. Thus, no standard countermeasure or specific drug with a definite target has been developed. ANXA1 is a member of the calcium-dependent, phospholipid binding protein superfamily, which was first discovered to be a secondary messenger downstream of the glucocorticoid receptor signaling pathway (30). ANXA1 is critical in the induction and regulation of anti-inflammatory treatment using glucocorticoids. ANXA1 also takes part in regulating phagocytosis, differentiation, proliferation, apoptosis and signaling transduction (31). Additionally, several animal model studies demonstrated the anti-inflammatory effect of ANXA1 $(32,33)$. Treatment of acute RILI using ANXA1 has not been described and its roles in RILI pathogenesis remain unclear.

The present study observed that glucocorticoid treatment is associated with increased ANXA1 in plasma. An increased concentration of ANXA1 in plasma following glucocorticoid treatment was associated with a more positive treatment outcome for RILI, indicating that ANXA1 may serve a beneficial role in the treatment of acute RILI.

ANXA1 in the plasma of patients with RILI was negatively correlated with the plasma levels of IL-6 and MPO, 
A

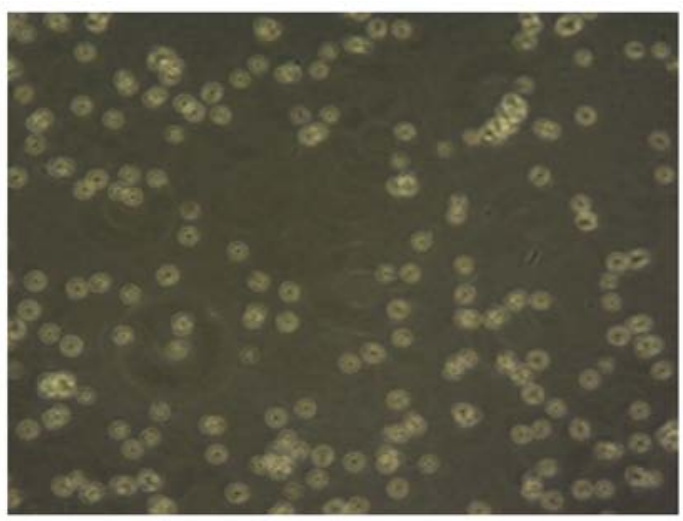

C

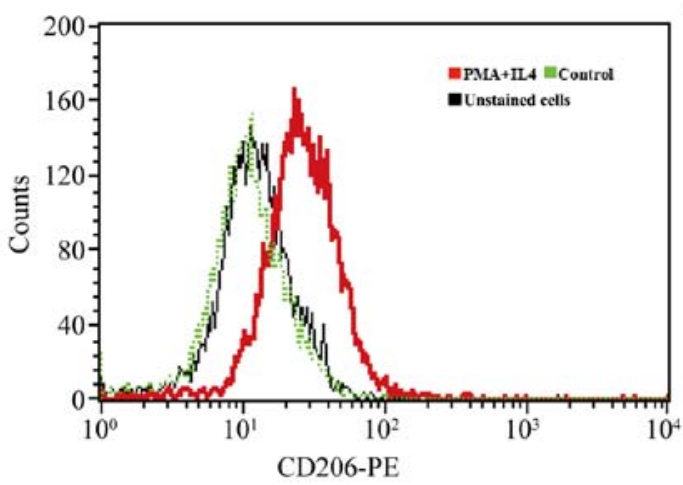

B

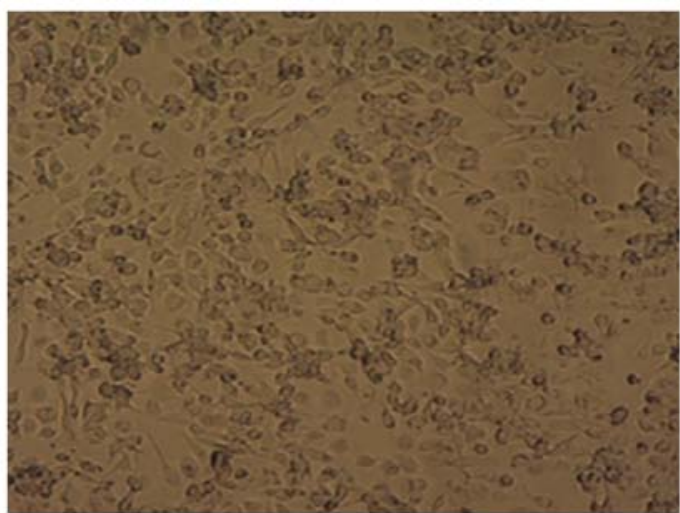

D

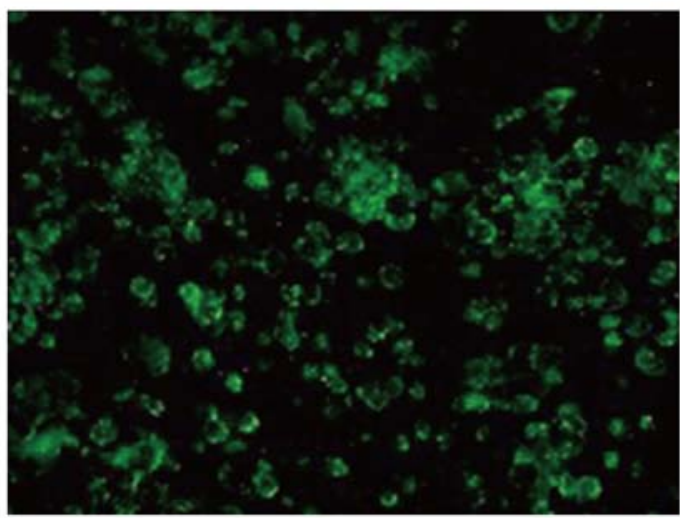

Figure 3. Differentiation of THP-1 cells to M2 macrophages. (A) THP-1 cells were circular or quasi-circular, growing in a state of suspension (magnification, x200). (B) THP-1 cells induced with phorbol 12-myristate 13-acetate and interleukin-4 became polygonal shape with outgrowth, and grew adherent to the plate wall (magnification, x200). (C) CD206 expression was observed by flow cytometry $48 \mathrm{~h}$ after induction. (D) Green fluorescent protein in macrophages transfected with pIRES2-ANXA1: The cells were spindle-like or pleomorphic (magnification, x200). ANXA1, annexin A1; CD206, macrophage mannose receptor 1 ; PE, phycoerythrin.

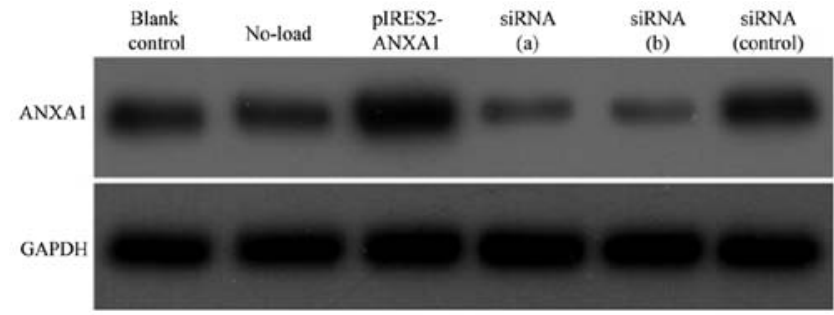

Figure 4. Expression of ANXA1 and GAPDH in untransfected macrophages (blank control) or macrophages transfected with pIRES2-GFP (No-load), pIRES2-ANXA1, siRNA (a), siRNA (b) or siRNA (control). ANXA1, annexin A1; GAPDH, glyceraldehyde 3-phosphate dehydrogenase; siRNA, short interfering RNA.

implying that ANXA1 may impact RILI treatment outcome by influencing the expression of these pro-inflammatory cytokines. IL-6 is an important pro-inflammatory factor, which is synthesized by activated alveolar macrophages, $\mathrm{T}$ helper 2 cells, lung fibroblasts and alveolar type II epithelial cells. IL- 6 is involved in the responses to lung injury and early-stage inflammation (34), and promotes the transition from $\mathrm{CD}^{+}$cells to $\mathrm{T}$ helper 17 cells, facilitating the accumulation and activation of neutrophils within the inflammatory area (35). MPO is mainly expressed by neutrophils and macrophages. During inflammation, neutrophils are activated and degranulated, and MPO is secreted into extracellular matrix.
Extracellular MPO is an alkaline protein with positive charge, which is easily adsorbed on the surface of negatively charged cell membrane (36). Hydrogen dioxide (H2O2) in extracellular matrix can aggregate to the site where the two bind, thus causing tissue damage (37). In addition, MPO is absorbed by vascular endothelial cells after being release from neutrophils, leading to vasculitis and further aggravating tissue damage (38). It is well known that radiotherapy can lead to the ionization of water molecules in the target area to produce $\mathrm{H} 2 \mathrm{O} 2$, so reactions catalyzed by MPO lead to oxidative injury and enhanced radiation-induced injury to the target tissue (39). In the present study, the baseline levels of IL-6 and MPO in RILI patients prior to glucocorticoid treatment were higher compared with those in the healthy controls, and the expression of the two factors was positively correlated. These observations are consistent with the previous literature $(40,41)$. The present findings support a previous report indicating that ANXA1 overexpression results in downregulation of IL-6 (42). A similar correlation between ANXA1 and IL-6 was also observed following fibroblastoma irradiation treatment (43). ANXA1 can induce apoptosis in neutrophils (44), and inhibit neutrophil migration and accumulation in the inflammatory area (45). In the present study, the expression of ANXA1 was increased in patients with RILI without an evident reduction of neutrophils in the circulation system, but with a significant reduction in the level of MPO. A similar result has been reported in a previous study (46). In a further study, more apoptotic neutrophils were observed when the observation 

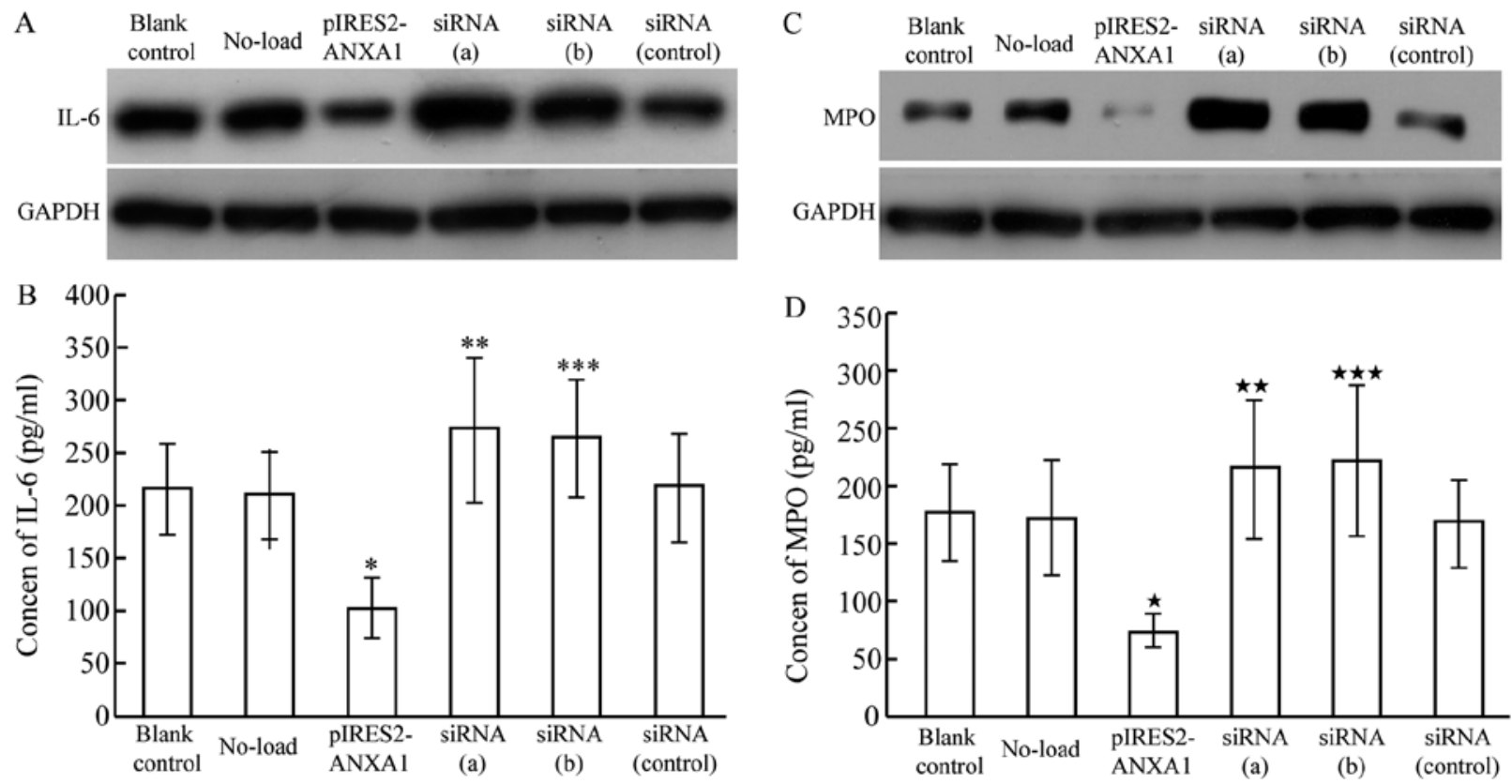

Figure 5. IL-6 and MPO expression in M2 macrophages transfected with pIRES2-ANXA1 or siRNA against ANXA1, siRNA (a) and siRNA (b). (A) IL-6 protein expression was decreased in macrophages with overexpression of ANXA1, while ANXA1 inhibition induced by siRNA led to increased IL-6 expression. (B) IL-6 in culture medium was decreased with overexpression of ANXA1 ("P<0.05 compared with blank control) and increased with siRNA-mediated ANXA1 inhibition ( ${ }^{* *} \mathrm{P}<0.05$ and ${ }^{* * *} \mathrm{P}<0.05$, compared with blank control). (C) MPO protein expression was decreased in macrophages with overexpression of ANXA1, while ANXA1 inhibition induced by siRNA led to increased IL-6 expression. (D) MPO in cell culture medium was decreased with overexpression of ANXA1 ( ${ }^{\star} \mathrm{P}<0.01$, compared with blank control), and increased with siRNA-mediated ANXA1 inhibition $\left({ }^{\star \star} \mathrm{P}<0.05\right.$ and ${ }^{\star \star \star} \mathrm{P}<0.05$ compared with blank control). ANXA1, annexin A1; IL-6, interleukin 6; MPO, myeloperoxidase; siRNA, short interfering RNA.

time frame was elongated, possibly due to the impaired function of the releasing granules of neutrophils following 4 weeks of increased ANXA1 expression, when no evident apoptosis was observed (47).

In the present study, ANXA1 was increased in the plasma of patients with acute RILI following glucocorticoid therapy. These results are consistent with several reports $(22,48)$. The present study also demonstrated that higher ANXA1 expression was associated with a beneficial treatment outcome for RILI following glucocorticoid administration, indicating an increased anti-inflammatory effect. A prior study reported that the anti-inflammatory effect of glucocorticoid was associated with induced expression of ANXA1 (49). Further studies demonstrated that ANXA1 gene knockdown in a mouse model of inflammation markedly upregulated the pro-inflammatory cytokine IL-6 (50), and an anti-inflammatory effect could not be achieved with glucocorticoid administration (51). Similar results were acquired when an antibody against ANXA1 was applied to inhibit its function (52). These results collectively demonstrate that the anti-inflammatory effect of glucocorticoid depends on the induction of ANXA1 expression, highlighting the potential of this protein as an anti-inflammatory therapy without the use of hormones.

In the present study, the overexpression of ANXA1 in macrophages inhibited the synthesis and secretion of IL-6 and MPO, while the inhibition of ANXA1 promoted these events, indicating that ANXA1 could serve an anti-inflammatory role, as previously reported $(19,44)$. ANXA1 alone has been reported to exert an anti-inflammatory effect. The ANXA1 N-terminal-derived peptide Ac2-26 can inhibit local and systematic inflammatory responses (53). Induction of compound
43, an agonist of the ANXA1 receptor, inhibits the expression of IL-6 in patients with rheumatoid arthritis and ameliorates bone damage by reducing the infiltration of inflammatory cells in synovial tissues (54). ANXA1 inhibits the activity of calcium-activated, phospholipid-dependent membrane-bound enzymes, particularly phospholipase A2 $(55,56)$. ANXA1 and its N-terminal fragment were also demonstrated to inhibit the synthesis of arachidonic acid derivatives $(57,58)$. ANXA1 restrains the inflammatory response induced by tumor necrosis factor- $\alpha$ by suppressing Rac-1-dependent NADPH oxidase in vascular epithelial cells (59). A more recent study demonstrated that ANXA1 could exert anti-inflammatory effects by inhibiting the transcriptional activity of nuclear factor- $\kappa \mathrm{B}(\mathrm{NF}-\kappa \mathrm{B})$, as ANXA1 binds specifically to the p65 subunit of NF- $\kappa B$, blocking binding to its target genes (49). However, conflicting findings have been reported. In one study, ANXA1 was found to promote inflammation by facilitating the transendothelial migration of neutrophils and monocytes (60). ANXA1 has also been demonstrated to mediate the activation of the extracellular signal-regulated kinase, c-Jun N-terminal kinase and $\mathrm{NF}-\kappa \mathrm{B}$ inflammatory pathways (61). Notably, one study indicated a role of endogenous ANXA1 in the anti-inflammatory effect, while exogenous ANXA1 induced inflammation (62). It is clear that more studies are required to clarify the exact role of ANXA1 in inflammation and RILI pathogenesis.

In conclusion, ANXA1 reduces the expression of IL-6 and inhibits the release of MPO from monocytes and macrophages. This anti-inflammatory effect may underscore the mechanism by which ANXA1 in the plasma of patients with RILI is associated with treatment outcome. Although glucocorticoids are common drugs in RILI treatment, the present study indicates 
the potential of ANXA1 to mimic the anti-inflammatory effect of glucocorticoids, which would potentially avoid certain adverse effects of this therapy.

\section{Acknowledgements}

Not applicable.

\section{Funding}

This study was supported by the Scientific Program of the Health and Family Planning Commission of Jiangsu Province (grant No. H2017076) and the Foundation of Jiangsu Provincial Medical Innovation Team (grant No. CXTDA2017042).

\section{Availability of data and materials}

All data generated or analyzed during the present study are included in this published article.

\section{Authors' contributions}

$\mathrm{GH}$ and $\mathrm{JH}$ conceived and were responsible for the design of the present study. GS, WX and KL analyzed and interpreted the patients' data. CD was responsible for the diagnosis of RILI and assessment of the curative effect based on imaging examinations. SZ and JY analyzed and interpreted the laboratory data. GH and SZ were the major contributors in writing the manuscript. All authors read and approved the present manuscript.

\section{Ethics approval and consent to participate}

This research was approved by the Ethics Committee of Taizhou People's Hospital, and written informed consent was provided by each patient prior to the study.

\section{Patient consent for publication}

All patients signed an informed consent for publication approved by the institutional Review Board.

\section{Competing interests}

The authors declare that they have no competing interests.

\section{References}

1. Graves PR, Siddiqui F, Anscher MS and Movsas B: Radiation pulmonary toxicity: From mechanisms to management. Semin Radiat Oncol 20: 201-207, 2010.

2. Han S, Gu F, Lin G, Sun X, Wang Y, Wang Z, Lin Q, Weng D, $\mathrm{Xu} \mathrm{Y}$ and Mao W: Analysis of clinical and dosimetric factors influencing radiation-induced lung injury in patients with lung cancer. J Cancer 6: 1172-1178, 2015.

3. Giridhar P, Mallick S, Rath GK and Julka PK: Radiation induced lung injury: Prediction, assessment and management. Asian Pac J Cancer Prev 16: 2613-2617, 2015.

4. Flechsig P, Dadrich M, Bickelhaupt S, Jenne J, Hauser K, Timke C, Peschke P, Hahn EW, Gröne HJ, Yingling J, et al: LY2109761 Attenuates radiation-induced pulmonary murine fibrosis via reversal of TGF- $\beta$ and BMP-associated proinflammatory and proangiogenic signals. Clin Cancer Res 18: 3616-3627, 2012.
5. Wang T, Mathew B, Wu X, Shimizu Y, Rizzo AN, Dudek SM, Weichselbaum RR, Jacobson JR, Hecker L and Garcia JG: Nonmuscle myosin light chain kinase activity modulates radiation-induced lung injury. Pulm Circ 6: 234-239, 2016.

6. Zhao DY, Qu HJ, Guo JM, Zhao HN, Yang YY, Zhang P, Cao K, Lei X, Cui JG, Liu C, et al: Protective effects of myrtol standardized against radiation-induced lung injury. Cell Physiol Biochem 38: 619-634, 2016.

7. Kainthola A, Haritwal T, Tiwari M, Gupta N, Parvez S, Tiwari M, Prakash H and Agrawala PK: Immunological aspect of radiation-induced pneumonitis, current treatment strategies, and future prospects. Front Immunol 8: 506, 2017.

8. Ghafoori P, Marks LB, Vujaskovic Z and Kelsey CR: Radiation-induced lung injury. Assessment, management, and prevention. Oncology (Williston Park) 22: 37-47, 2008.

9. Sun Y, Du YJ, Zhao H, Zhang GX, Sun N and Li XJ: Protective effects of ulinastatin and methylprednisolone against radiation-induced lung injury in mice. J Radiat Res 57: 505-511, 2016.

10. Oray M, Abu Samra K, Ebrahimiadib N, Meese H and Foster CS: Long-term side effects of glucocorticoids. Expert Opin Drug Saf 15: 457-465, 2016.

11. Kim JH, Jenrow KA and Brown SL: Mechanisms of radiation-induced normal tissue toxicity and implications for future clinical trials. Radiat Oncol J 32: 103-115, 2014.

12. Xu T, Zhang Y, Chang P, Gong S, Shao L and Dong L: Mesenchymal stem cell-based therapy for radiation-induced lung injury. Stem Cell Res Ther 9: 18, 2018.

13. Ding NH, Li JJ and Sun LQ: Molecular mechanisms and treatment of radiation-induced lung fibrosis. Curr Drug Targets 14: 1347-1356, 2013

14. Straub JM, New J, Hamilton CD, Lominska C, Shnayder Y and Thomas SM: Radiation-induced fibrosis: Mechanisms and implications for therapy. J Cancer Res Clin Oncol 141: 1985-1994, 2015

15. Siva S, MacManus M, Kron T, Best N, Smith J, Lobachevsky P, Ball D and Martin O: A pattern of early radiation-induced inflammatory cytokine expression is associated with lung toxicity in patients with non-small cell lung cancer. PLoS One 9: e109560, 2014.

16. Zhang XJ, Sun JG, Sun J, Ming H, Wang XX, Wu L and Chen ZT: Prediction of radiation pneumonitis in lung cancer patients: A systematic review. J Cancer Res Clin Oncol 138: 2103-2116, 2012.

17. Brooks AC, Rickards KJ and Cunninggham FM: Modulation of equine neutrophil adherence and migration by the annexin-1 derived N-terminal peptide, Ac2-26. Vet Immunol Immunopathol 145: 214-222, 2012.

18. Bena S, Brancaleone V, Wang JM, Perretti M and Flower RJ: Annexin A1 interaction with the FPR2/ALX receptor: Identification of distinct domains and downstream associated signaling. J Biol Chem 287: 24690-24697, 2012.

19. Spurr L, Nadkarni S, Pederzoli-Ribeil M, Goulding NJ, Perretti M and D'Acquisto F: Comparative analysis of Annexin A1-formyl peptide receptor 2/ALX expression in human leukocyte subsets. Int Immunopharmacol 11: 55-66, 2011.

20. Perretti $M$ and Dalli J: Exploiting the annexin A 1 pathway for the development of novel anti-inflammatory therapeutics. Br J Pharmacol 158: 936-946, 2009.

21. Tucker SL, Jin H, Wei X, Wang S, Martel MK, Komaki R, Liu HH, Mohan R, Chen Y, Cox JD and Liao Z: Impact of toxicity grade and scoring system on the relationship between mean lung dose and risk of radiation pneumonitis in a large cohort of patients with non-small cell lung cancer. Int J Radiat Oncol Biol Phys 77: 691-698, 2010.

22. Han G, Lu K, Huang J, Ye J, Dai S, Ye Y and Zhang L: Effect of Annexin A1 gene on the proliferation and invasion of esophageal squamous cell carcinoma cells and its regulatory mechanisms. Int J Mol Med 39: 357-363, 2017.

23. Dehai C, Bo P, Qiang T, Lihua S, Fang L, Shi J, Jingyan C, Yan Y, Guangbin W and Zhenjun Y: Enhanced invasion of lung adenocarcinoma cells after co-culture with THP-1-derived macrophages via the induction of EMT by IL-6. Immunol Lett 160: 1-10, 2014

24. Xu H, Wang X and Wang W: Functional suppression of macrophages derived from THP-1 cells by environmentally-relevant concentrations of arsenite. Comp Biochem Physiol C Toxicol Pharmacol 214: 36-42, 2018.

25. Tedesco S, De Majo F, Kim J, Trenti A, Trevisi L, Fadini GP, Bolego C,Zandstra PW, Cignarella A and Vitiello L: Convenience versus biological significance: Are PMA-differentiated THP-1 cells a reliable substitute for blood-derived macrophages when studying in vitro polarization? Front Pharmacol 9: 71, 2018. 
26. Draijer C, Boorsma CE, Robbe P, Timens W, Hylkema MN, Ten Hacken NH, van den Berge M, Postma DS and Melgert BN: Human asthma is characterized by more IRF5+ M1 and CD206+ M2 macrophages and less IL-10+ M2-like macrophages around airways compared with healthy airways. J Allergy Clin Immunol 140: 280-283.e3, 2017.

27. Du Q, Tsuboi N, Shi Y, Ito S, Sugiyama Y, Furuhashi K, Endo N, Kim H, Katsuno T, Akiyama S, et al: Transfusion of CD206+ M2 macrophages ameliorates antibody-mediated glomerulonephritis in mice. Am J Pathol 186: 3176-3188, 2016.

28. Udeabor SE, Adisa AO, Orlowska A, Sader RA and Ghanaati S Tumor-associated macrophages, angiogenesis, and tumor cell migration in oral squamous cell carcinoma. Ann Afr Med 16 181-185, 2017.

29. Petrella A, Festa M, Ercolino SF, Zerilli M, Stassi G, Solito E and Parente L: Induction of annexin-1 during TRAIL-induced apoptosis in thyroid carcinoma cells. Cell Death Differ 12: 1358-1360, 2005.

30. Ng FS, Wong KY, Guan SP, Mustafa FB, Kajiji TS, Bist P, Biswas SK, Wong WS and Lim LH: Annexin-1-deficient mice exhibit spontaneous airway hyperresponsiveness and exacerbated allergen-specific antibody responses in a mouse model of asthma. Clin Exp Allergy 41: 1793-1803, 2011.

31. Bizzarro V, Petrella A and Parente L: Annexin A1: Novel roles in skeletal muscle biology. J Cell Physiol 227: 3007-3315, 2012.

32. Galvão I, Vago JP, Barroso LC, Tavares LP, Queiroz-Junior CM, Costa VV, Carneiro FS, Ferreira TP, Silva PM, Amaral FA, et al: Annexin A1 promotes timely resolution of inflammation in murine gout. Eur J Immunol 47: 585-596, 2017.

33. Locatelli I, Sutti S, Jindal A, Vacchiano M, Bozzola C, Reutelingsperger C, Kusters D, Bena S, Parola M, Paternostro C, et al: Endogenous annexin A1 is a novel protective determinant in nonalcoholic steatohepatitis in mice. Hepatology 60: 531-544, 2014

34. Hong ZY, Song KH, Yoon JH, Cho J and Story MD: An experimental model-based exploration of cytokines in ablative radiation-induced lung injury in vivo and in vitro. Lung 193 409-419, 2015

35. Lowes MA, Russell CB, Martin DA, Towne JE and Krueger JG: The IL-23/T17 pathogenic axis in psoriasis is amplified by keratinocyte responses. Trends Immunol 34: 174-181, 2013.

36. Klinke A, Nussbaum C, Kubala L, Friedrichs K, Rudolph TK, Rudolph V, Paust HJ, Schröder C, Benten D, Lau D, et al: Myeloperoxidase attracts neutrophils by physical forces. Blood 117: 1350-1358, 2011.

37. Klebanoff SJ: Myeloperoxidase: Friend and foe. J Leukoc Biol 77: 598-625, 2005.

38. Jerke U, Rolle S, Purfürst B, Luft FC, Nauseef WM and Kettritz R: $\beta 2$ integrin-mediated cell-cell contact transfers active myeloperoxidase from neutrophils to endothelial cells. J Biol Chem 288: 12910-12919, 2013.

39. MacNaughton JI: Regional oxygenation and radiotherapy: A study of the degradation of infused hydrogen peroxide. Int J Radiat Biol Relat Stud Phys Chem Med 19: 405-413, 1971.

40. Barthelemy-Brichant N, Bosquee L, Cataldo D, Corhay JL, Gustin M, Seidel L, Thiry A, Ghaye B, Nizet M, Albert A, et al Increased IL- 6 and TGF- $\beta 1$ concentrations in bronchoalveolar lavage fluid associated with thoracic radiotherapy. Int J Radial Oncol Biol Phys 58: 758-767, 2004.

41. Chen Y, Williams J, Ding I, Hernady E, Liu W, Smudzin T, Finkelstein JN, Rubin P and Okunieff P: Radiation pneumonitis and early circulatory cytokine markers. Semin Radiat Oncol 12 (1 Suppl 1): S26-S33, 2002.

42. Girol AP, Mimura KK, Drewes CC, Bolonheis SM, Solito E, Farsky SH, Gil CD and Oliani SM: Anti-inflammatory mechanisms of the annexin A1 protein and its mimetic peptide Ac2-26 in models of ocular inflammation in vivo and in vitro. J Immunol 190: 5689-5701, 2013.

43. Desai S, Srambikkal N, Yadav HD, Shetake N, Balla MM, Kumar A, Ray P, Ghosh A and Pandey BN: Molecular understanding of growth inhibitory effect from irradiated to bystander tumor cells in mouse fibrosarcoma tumor model. PLoS One 11: e0161662, 2016.

44. Vago JP, Nogueira CR, Tavares LP, Soriani FM, Lopes F, Russo RC, Pinho V, Teixeira MM and Sousa LP: Annexin A1 modulates natural and glueocorticoid-induced resolution of inflammation by enhancing neutrophil apoptosis. J Leukoc Biol 92: 249-258, 2012.
45. Leoni G, Gripentrog J, Lord C, Riesselman M, Sumagin R, Parkos CA, Nusrat A and Jesaitis AJ: Human neutrophil formyl peptide receptor phosphorylation and the mucosal inflammatory response. J Leukoc Biol 97: 87-101, 2015.

46. Dalli J, Norling LV, Renshaw D, Cooper D, Leung KY and Perretti M: Annexin 1 mediates the rapid anti-inflammatory effects of neutrophil-derived microparticles. Blood 112: 2512-2519, 2008

47. Sugimoto MA, Vago JP, Teixeira MM and Sousa LP: Annexin $\mathrm{A} 1$ and the resolution of inflammation: Modulation of neutrophil recruitment, apoptosis, and clearance. J Immunol Res 2016: 8239258, 2016

48. Chen Z, Yoshihara E, Son A, Matsuo Y, Masutani H, Sugie K, Maeda M and Yodoi J: Differential roles of Annexin A1 (ANXA1/lipocorton-1/lipomodulin) and thioredoxin binding protein-2 (TBP-2/VDUP1/TXNIP) in glucocorticoid signaling of HTLV-I-transformed T cells. Immunol Lett 131: 11-18, 2010.

49. Zhang Z, Huang L, Zhao W and Rigas B: Annexin 1 induced by anti-inflammatory drugs binds to NF-kappaB and inhibits its activation: Anticancer effects in vitro and in vivo. Cancer Res 70: 2379-2388, 2010.

50. Yang YH, Aeberli D, Dacumos A, Xue JR and Morand EF: Annexin-1 regulates macrophage IL-6 and TNF via glucocorticoid-induced leucine zipper. J Immunol 183: 1435-1445, 2009.

51. Patel HB, Kornerup KN, Sampaio AL, D'Acquisto F, Seed MP, Girol AP, Gray M, Pitzalis C, Oliani SM and Perretti M: The impact of endogenous annexin A1 on glucocorticoid control of inflammatory arthritis. Ann Rheum Dis 71: 1872-1880, 2012.

52. Yang YH, Morand EF, Getting SJ, Paul-Clark M, Liu DL, Yona S, Hannon R, Buckingham JC, Perretti M and Flower RJ: Modulation of inflammation and response to dexamethasone by Annexin 1 in antigen-induced arthritis. Arthritis Rheum 50: 976-984, 2004

53. Stuqui B, de Paula-Silva M, Carlos CP, Ullah A, Arni RK, Gil CD and Oliani SM: Ac2-26 mimetic peptide of Annexin A1 inhibits local and systemic inflammatory processes induced by bothropsmoojeni venom and the lys- 49 phospholipase A2 in a rat model. PLoS One 10: e0130803, 2015.

54. Kao W, Gu R, Jia Y, Wei X, Fan H, Harris J, Zhang Z, Quinn J, Morand EF and Yang YH: A formyl peptide receptor agonist suppresses inflammation and bone damage in arthritis. Br J Pharmacol 171: 4087-4096, 2014.

55. McArthur S, Gobbetti T, Kusters DH, Reutelingsperger CP, Flower RJ and Perretti M: Definition of a novel pathway centered on lysophosphatidic acid to recruit monocytes during the resolution phase of tissue inflammation. J Immunol 195: 1139-1151, 2015.

56. Headland SE and Norling LV: The resolution of inflammation: Principles and challenges. Semin Immunol 27: 149-160, 2015.

57. Yang Y, Liu Y, Yao X, Ping Y, Jiang T, Liu Q, Xu S, Huang J, Mou H, Gong W, et al: Annexin 1 released by necrotic human glioblastoma cells stimulates tumor cell growth through the formyl peptide receptor 1. Am J Pathol 179: 1504-1512, 2011.

58. Protzel C, Richter M, Poetsch M, Kakies C, Zimmermann U, Woenckhaus C, Klebingat KJ, Hakenberg OW and Giebel J: The role of annexins I, II and IV in tumor development, progression and metastasis of human penile squamous cell carcinomas. World J Urol 29: 393-398, 2011.

59. Peshavariya HM, Taylor CJ, Goh C, Liu GS, Jiang F, Chan EC and Dusting GJ: Annexin peptide Ac2-26 suppresses TNFo-induced inflammatory responses via inhibition of Rac1-dependent NADPH oxidase in human endothelial cells. PLoS One 8: e60790, 2013

60. Williams SL, Milne IR, Bagley CJ, Gamble JR, Vadas MA, Pitson SM and Khew-Goodall Y: A proinflammatory role for proteolytically cleaved annexin A1 in neutrophil transendothelial migration. J Immunol 185: 3057-3063, 2010.

61. Jia Y, Morand EF, Song W, Cheng Q, Stewart A and Yang YH: Regulation of lung fibroblast activation by annexin A1. J Cell Physiol 228: 476-484, 2013.

62. Yang YH, Song W, Deane JA, Kao W, Ooi JD, Ngo D, Kitching AR, Morand EF and Hickey MJ: Deficiency of annexin $\mathrm{A} 1$ in $\mathrm{CD} 4+\mathrm{T}$ cells exacerbates T cell-dependent inflammation. J Immunol 190: 997-1007, 2013. 